\title{
AN EMPIRICAL EXAMINATION OF THE DIVERSIFICATION \\ BENEFITS OF U.K. INTERNATIONAL EQUITY CLOSED-END FUNDS
}

Jonathan Fletcher

University of Strathclyde

Key words: Diversification Benefits, Bayesian Analysis, Closed-End Funds

JEL classification: G11, G12

Helpful comments received from two anonymous reviewers.

This draft: October 2017

Address correspondence to Professor J. Fletcher, Department of Accounting and Finance, University of Strathclyde, Stenhouse Wing, 199 Cathedral Street, Glasgow, G4 0QU, United Kingdom, phone: +44 (0) 141548 4963, fax: +44 (0) 552 3547, email: j.fletcher@strath.ac.uk 


\section{AN EMPIRICAL EXAMINATION OF THE DIVERSIFICATION BENEFITS OF U.K. INTERNATIONAL EQUITY CLOSED-END FUNDS \\ ABSTRACT}

I use the Bayesian approach of Wang(1998) to examine the diversification benefits of international equity U.K. closed-end funds (CEF) in the presence of market frictions. No short selling constraints substantially reduce, and in some cases eliminate the diversification benefits of CEF. However, adjusting for higher trading costs in the benchmark assets, the diversification benefits of the funds are significant. The paper also finds that when comparing to the international equity exchange-traded funds (ETF), that both groups of funds are necessary to maximize the benefits of international diversification. 


\section{Introduction}

The classic studies of Grubel(1968) and Lessard(1973) highlight the benefits of international portfolio diversification. A recent study by Hodrick and Zhang(2014) find that the diversification benefits continue to exist in developed equity markets even in the most recent period. Investors can gain access to these diversification benefits either through direct investment in these markets or indirectly through managed funds such as international equity closed-end funds (CEF) or open-end funds (OEF). Indirect investment is probably the most likely route for retail investors but could also be for institutional investors ${ }^{1}$.

In this study, I examine the diversification benefits provided by international equity CEF. International equity CEF are an important group of funds. As at the end of December 2016, there were $104 \mathrm{CEF}$ available with a combined market value of $£ 46,549 \mathrm{bn}$ (Association of Investment Companies (AIC)). Compared to domestic U.K. equity CEF, there is both a greater number of funds and a much higher combined market value ${ }^{2}$. A number of international CEF have a long history, such as the Foreign and Colonial Trust which dates back to 1868 and the Alliance trust which dates from 1888. U.K. CEF differ from U.S. CEF in that the main shareholders are institutional investors ${ }^{3}$.

\footnotetext{
${ }^{1}$ Parwada and Siaw(2014) find that institutional investors in U.S. closed-end funds tend not to invest in the same stocks as the CEF. Institutional investors use CEF to diversify into assets where they tend not to directly invest in.

${ }^{2}$ This pattern differs from U.S. CEFs, where the combined market value of domestic equity CEF is larger than international equity CEF. Another interesting difference with the U.S., is that there are very few bond CEF in the U.K.
${ }^{3}$ Parwada and Siaw(2014) find that institutional ownership has increased in U.S. CEF over time and is greatest in foreign equity funds.


CEF provide a number of advantages to investors. Cherkes, Sagi and Stanton(2009) argue that CEF deliver liquidity benefits to investors in that the funds can invest in illiquid assets but the underlying CEF shares can be liquid. CEF are able to do this more effectively than OEF since CEF are not subject liquidity trading with cash flows coming in and out of the fund. Elton, Gruber, Blake and Shacher(2013) find that U.S. bond CEF outperform matched OEF (offered by the same fund family) due to being able to use leverage. CEF are not subject to liquidity trading that $\mathrm{OEF}$ are due to cash flows that hurts fund performance (Edelen(1999)) and do not need to hold so much cash (Chordia(1996)). Due to the performance-flow relation in OEF, fund managers are likely to avoid long-term mispricing opportunities (Shleifer and Vishny(1997), Stein(2005)). Giannetti and Kahraman(2017) find that U.S. CEF are much more likely than OEF to trade in fire sale stocks (especially small stocks and stocks with high idiosyncratic risk) and at times when aggregate noise trader demand is low for certain undervalued stocks. Giannetti and Kahraman find that CEF significantly outperform OEF using Net Asset Value (NAV) returns ${ }^{4}$.

A drawback of using CEF to access the benefits of international diversification is the existence of the CEF premiums/discounts, where the fund NAV differs from the share price. Since CEF trade in local stock markets, they are affected by local factors as well as global factors. Bekaert and Urias(1996) examine the diversification benefits of U.S. and U.K. emerging market CEF and find U.K. funds provide significant diversification benefits but U.S. funds do not. Errunza, Hogan and Hung(1999) find that CEF in addition with other securities provide significant diversification benefits. A recent study by $\mathrm{Cao}, \mathrm{Fu}$ and

\footnotetext{
4 There are disadvantages in CEF. Agency costs are higher in CEF as investors cannot redeem their shares at NAV (Fama and Jensen(1983)). Wu, Wermers and Zechner(2016) find that shareholders in U.S. CEF find it difficult to extract rents from skilled managers and in disciplining unskilled managers.
} 
Jin(2017) find significant diversification benefits for U.S. CEF. They also examine whether these funds become redundant in presence of international exchange-traded funds (ETF). Cao et al find neither group of funds is redundant in the presence of the other group of funds.

The prior studies of the diversification benefits of international CEF have primarily focused on country funds and have not examined whether these benefits persist in the face of market frictions such as short selling constraints and/or trading costs. A number of studies have found that taking account of market frictions has a significant impact on a number of applications such as emerging market diversification (De Roon, Nijman and Werker(2001), Li, Sarkar and Wang(2003)), estimating the Hansen and Jagannathan(1991) volatility bounds (He and Modest(1995), Luttmer(1996)), and the ability of asset pricing models to explain stock return predictability (De Roon and Szymanowska(2012)). This study fills this gap in the literature.

I use the Bayesian approach of Wang(1998) to examine the diversification benefits provided by a large sample of U.K. international equity CEF in the presence of market frictions. An important consideration here is that the benchmark assets used for the domestic investment universe is likely to have higher trading costs than the CEF. Since I use the stock returns of the CEF, which are net of all fund expenses and trading costs, the only cost lies in buying the funds. These costs are likely to be trivial relative to the cost of the benchmark assets, which can involve hundreds of stocks, includes smaller companies, and can involve high portfolio turnover. In addition to examining the impact of market frictions on the diversification benefits of the CEF, my study extends the prior literature by using a broader range of international equity CEF from a different market. Harvey(2017) and Hou, Xue and Zhang(2017) highlight the importance of replication studies in Finance, which is common in other fields of science. 
My study examines three main research questions. First, I examine whether international equity CEF provide significant diversification benefits in the presence of no short selling constraints. I use six international equity investment sector CEF portfolios and estimate the diversification benefits as the increase in the Certainty Equivalent Return (CER) performance of adding the CEF portfolios to a domestic investment universe consisting of domestic benchmark assets. I use three sets of benchmark assets including the market index, six size/book-to-market (BM) portfolios, and six size/momentum portfolios ${ }^{5}$. Second, I examine the impact of higher trading costs on the benchmark assets has on the diversification benefits of the CEF portfolios. Third, following Pennathur, Delcoure and Anderson(2002), Miffre(2007), and Cao et al(2017) among others, I compare the diversification benefits of the CEF portfolios to international equity ETF portfolios ${ }^{6}$. I extend these studies by examining the impact of market frictions on the diversification benefits on the CEF and ETF.

There are three main findings in my study. First, no short selling constraints lead to a substantial reduction in the diversification benefits provided by CEFs. When the benchmark investment universe includes size/momentum portfolios, all of the diversification benefits of CEF portfolios are eliminated with no short selling constraints. Second, adjusting for higher trading costs in the benchmark assets has a significant impact on the diversification benefits of CEF portfolios. The CEF portfolios now provide significant diversification benefits relative to all three benchmark investment universes even with no short selling constraints. Third, I find that both CEF and ETF portfolios play an important role in maximizing the diversification benefits for investors. The dominant weights are in the two CEF and ETF North America portfolios. My study suggests that market frictions play a significant role in

\footnotetext{
${ }^{5}$ The size/BM and size/momentum portfolios are the underlying portfolios in the formation of the Fama and French(1993) and Carhart(1997) factors.

${ }^{6}$ I thank a reviewer for suggesting an examination of this issue.
} 
the diversification benefits of international equity $\mathrm{CEF}$, and there is support for significant diversification benefits provided by these funds.

The paper is organized as follows. Section II presents the research method. Section III describes the data used in my study. Section IV reports the empirical results. The final section concludes.

\section{Research Method}

I evaluate the diversification benefits of international CEF and ETF using the meanvariance approach of Markowitz(1952). Studies by Bekaert and Urias(1996), Li et al(2003), Ehling and Ramos(2006), Eiling, Gerard, Hillion and De Roon(2012), Hodrick and Zhang(2014), and Liu(2016) among others use the mean-variance approach to evaluate the benefits of international portfolio diversification. They examine whether there is a significant shift between two mean-variance frontiers when international assets are added to a benchmark investment universe.

Assuming the existence of a risk-free asset, the mean-variance approach of Markowitz(1952) assumes that investors select a $(\mathrm{N}, 1)$ vector of risky assets $(\mathrm{x})$ to:

$$
\operatorname{Max} x^{\prime} u-(\gamma / 2) x^{\prime} V x
$$

where $\mathrm{u}$ is a $(\mathrm{N}, 1)$ vector of expected excess returns on the $\mathrm{N}$ assets, $\mathrm{V}$ is the $(\mathrm{N}, \mathrm{N})$ covariance matrix, and $\gamma$ is the risk aversion of the investor. Equation (1) implies that the remainder of the investor's wealth is put into the risk-free asset such that $x^{\prime} \mathrm{e}+\mathrm{x}_{\mathrm{rf}}=1$, where e is a $(\mathrm{N}, 1)$ vector of ones and $\mathrm{x}_{\mathrm{rf}}$ is the weight in the risk-free asset. When the investor faces portfolio constraints, additional restrictions can be added to equation (1). In most of my empirical tests, $I$ impose no short selling constraints on the $N$ risky assets $\left(x_{i} \geq 0, i=1, \ldots, N\right)$ and the risk-free asset ( $\left.x^{\prime} \mathrm{e} \leq 1\right)$.

To evaluate the diversification benefits provided by the international equity CEF and ETF, I use the CER performance measure, which is the mean-variance objective function of 
equation $(1)^{7}$. Alternative performance measures can be used such as the Sharpe(1966) measure, the increase in expected return (Kandel, McCulloch and Stambaugh(1995), Wang(1998)), the reduction in variance (Basak, Jagannathan and Sun(2002)) among others. These measures provide relevant information on the diversification benefits. However the CER measure is most relevant for a mean-variance investor who maximizes the meanvariance objective function.

Define $\mathrm{K}$ as the number of risky assets in the benchmark investment universe, which includes the domestic assets, and N-K is the number of risky assets (international equity CEF and/or ETF) added to the benchmark investment universe. I estimate the diversification benefits of the CEF or ETF portfolios as the increase in CER performance of adding these portfolios to the benchmark investment universe. The measure is given by:

$$
\operatorname{DCER}=\left(x^{\prime} u-(\gamma / 2) * x^{\prime} V^{*} x\right)-\left(x_{b}{ }^{\prime} u-(\gamma / 2) * x_{b}{ }^{\prime} V^{*} x_{b}\right)
$$

where $x_{b}$ is a $(N, 1)$ vector where the first $K$ cells are the optimal portfolio weights in the benchmark investment universe and the remaining $(\mathrm{N}-\mathrm{K})$ cells are zero. If the CEF or ETF portfolios do not provide diversification benefits, then the DCER measure will equal zero. I set the risk aversion $(\gamma)$ levels equal to 1, 3 and 5 similar to Tu and Zhou(2011) and Kan et $\operatorname{al}(2017)$.

There are two main methods to estimate the diversification benefits and evaluate the statistical significance using the mean-variance approach in the presence of market frictions. The first relies on classical statistics, which provides asymptotic tests. Basak et al(2002) and Briere, Drut, Mignon, Oosterlinck and Szafarz(2013) propose two different mean-variance inefficiency measures and derive the corresponding asymptotic distributions. De Roon et

\footnotetext{
${ }^{7}$ The CER measure is commonly used to evaluate the performance of mean-variance trading strategies such as DeMiguel, Garlappi and Uppal(2009), Tu and Zhou(2011), and Kan, Wang and Zhou(2017) among others.
} 
al(2001) derive a test of mean-variance spanning ${ }^{8}$ in the presence of short selling constraints ${ }^{9}$ and transaction costs.

The second method is the Bayesian approach of Wang(1998) and Li et al(2003) who extend the approach of Kandel et al(1995) to allow for portfolio constraints. Li et al point out that the Bayesian approach has a number of advantages relative to the asymptotic tests. First, the Bayesian approach is easier to implement than the asymptotic tests. A wide range of performance measures can be used and different portfolio constraints can be applied ${ }^{10}$. Second, the uncertainty of finite samples is incorporated into the posterior distribution. Third, the asymptotic tests rely on a linear approximation using the delta method of a nonlinear function when there are short selling constraints. In contrast, the Bayesian approach uses the exact nonlinear function.

\footnotetext{
${ }^{8}$ Mean-variance spanning is a stronger condition that mean-variance efficiency when no riskfree asset exists. Mean-variance spanning occurs when the mean-variance frontiers of the K benchmark assets and the $\mathrm{N}$ risky assets are the same. De Roon and Nijman(2001) and Kan and Zhou(2012) provide excellent reviews of tests of mean-variance spanning when the only portfolio constraint is the budget constraint.

9 De Roon and Karehnke(2017) develop mean-variance skewness spanning tests in the presence of short selling constraints.

${ }^{10}$ When estimating the mean-variance frontier in the presence of short selling constraints, the frontier is a piecewise parabola in mean-variance space (Best and Grauer(1990)) and consists of distinct intervals. Mean-variance spanning needs to hold within each distinct interval (De Roon et al(2001)). This leads to a much larger number of testable restrictions in the De Roon et al test.
} 
I use the Bayesian approach of $\mathrm{Wang}(1998)^{11}$ to estimate the magnitude and statistical significance of the diversification benefits using the DCER measure. The analysis assumes that the $\mathrm{N}$ asset excess returns have a multivariate normal distribution ${ }^{12}$. I assume a noninformative prior about the expected excess returns $\mathrm{u}$ and the covariance matrix $\mathrm{V}$. Define $\mathrm{u}_{\mathrm{s}}$ and $\mathrm{V}_{\mathrm{s}}$ as the sample moments of the expected excess returns and covariance matrix, and $\mathrm{R}$ as the $(\mathrm{T}, \mathrm{N})$ matrix of excess returns on the $\mathrm{N}$ assets. The posterior probability density function is given by:

$$
\mathrm{p}(\mathrm{u}, \mathrm{V} \mid \mathrm{R})=\mathrm{p}\left(\mathrm{u} \mid \mathrm{V}, \mathrm{u}_{\mathrm{s}}, \mathrm{T}\right) \bullet \mathrm{p}\left(\mathrm{V} \mid \mathrm{V}_{\mathrm{s}}, \mathrm{T}\right)
$$

where $\mathrm{p}\left(\mathrm{u} \mid \mathrm{V}, \mathrm{u}_{\mathrm{s}}, \mathrm{T}\right)$ is the conditional distribution of a multivariate normal $\left(\mathrm{u}_{\mathrm{s}},(1 / \mathrm{T}) \mathrm{V}\right)$ distribution and $\mathrm{p}\left(\mathrm{V} \mid \mathrm{V}_{\mathrm{s}}, \mathrm{T}\right)$ is the marginal posterior distribution that has an inverse Wishart(TV, T-1) distribution (Zellner, 1971)).

I use the Monte Carlo method proposed by Wang(1998) to approximate the posterior distribution of the DCER measure. First, a random V matrix is drawn from an inverse Wishart $\left(\mathrm{TV}_{\mathrm{s}}, \mathrm{T}-1\right)$ distribution. Second, a random $\mathrm{u}$ vector is drawn from a multivariate normal $\left(\mathrm{u}_{\mathrm{s}},(1 / \mathrm{T}) \mathrm{V}\right)$ distribution. Third, given the $\mathrm{u}$ and $\mathrm{V}$ from steps 1 and 2 , the DCER measure from equation (2) is estimated. Fourth, steps 1 to 3 are repeated 1,000 times as in

11 Recent applications of the Bayesian approach include Hodrick and Zhang(2014) and $\operatorname{Liu}(2016)$.

${ }^{12}$ Multivariate normality is commonly assumed in studies examining issues in mean-variance optimization such as Kan and Smith(2008), Tu and Zhou(2011), and Kan et al(2017) among others. We can view multivariate normality as a working approximation for monthly excess returns. Kroll, Levy and Markowitz(1984), Grauer and Hakansson(1993), and Best and Grauer(2011) find that over short return horizons the mean-variance approximation to expected utility works reasonably well. 
Hodrick and Zhang(2014) to generate the approximate posterior distribution of the DCER measure. The average value from the posterior distribution of the DCER measure is the average diversification benefits provided by funds. The values of the $5^{\text {th }}$ percentile and $10^{\text {th }}$ percentile of the posterior distribution of the DCER measure provides a statistical test of whether the average DCER measure equals zero (Hodrick and Zhang(2014)).

Li et al(2003) also point out that the Bayesian approach provides the approximate posterior distribution of the optimal portfolio weights. Britten-Jones(1999) and Kan and Smith(2008) derive the sampling distribution of optimal portfolio weights for unconstrained mean-variance portfolio strategies. The Bayesian approach provides a way of estimating the sampling distribution of optimal portfolio weights for constrained mean-variance portfolio strategies.

The analysis can be modified to accommodate trading costs. This issue is important as the benchmark assets I use are likely to have higher trading costs than the CEF and ETF portfolios since I use stock returns of funds. The use of stock returns implies that the fund returns capture the value added of the fund. Aragon and Ferson(2008) point out that we can test for the value added of the fund when using fund returns net of all trading costs and expenses. The use of stock returns by CEFs depends not only on any performance ability, trading costs, expenses, but also the fund premium ${ }^{13}$ and is most relevant for capturing the diversification benefits for investors. Since the CEF returns are net of all costs and expenses, the cost of the CEF portfolio (ignoring short selling) is the cost of buying the individual funds, which is likely to be trivial compared to the benchmark assets, given the small number

${ }^{13}$ Dimson and Minio-Paluello(2002) and Cherkes(2012) provide excellent reviews of the alternative explanations of the CEF premium. Recent theoretical models include Berk and Stanton(2007), Cherkes et al(2009) and Jarrow and Protter(2017). 
of funds in each portfolio. In contrast, the benchmark assets can include hundreds of stocks, include smaller companies, and can require high portfolio turnover.

I incorporate trading costs following the approach of De Roon et al(2001). De Roon et al, following Luttmer(1996), show that trading costs can be included by adjusting the returns of the assets. I set the trading costs of the CEF portfolios to zero and adjust the returns of the benchmark assets to reflect the impact of higher trading costs. For the constrained portfolio strategies, I adjust the returns of the benchmark assets as $t_{c} R_{i t}$, where $t_{c}$ $=1 /(1+\mathrm{a}), \mathrm{a}$ is the proportional transaction $\operatorname{cost}^{14}$, and $\mathrm{R}_{\mathrm{it}}$ is the gross return (1+return) of benchmark asset $\mathrm{i}$ at time $\mathrm{t}$. I then calculate the adjusted excess returns ${ }^{15}$ and proceed with the Bayesian approach. I consider two cases of trading costs in the benchmark assets. First, I set the proportional transaction cost to 50 basis points on the benchmark assets as in Balduzzi and Lynch(1999) and DeMiguel et al(2009). Second, I set the proportional transaction cost to 10 basis points on the size/BM portfolios, since the size/BM portfolios will have a much smaller turnover than the size/momentum portfolios (Frazzini, Israel and Moskowitz(2014)).

\section{Data}

\section{A) Sample of U.K. International Closed-End Equity Funds and Exchange Traded Funds}

My study takes the perspective of a U.K. investor. I examine whether international equity CEF and ETF that trade in U.K. markets enhances the mean-variance performance when the investor is initially restricted to the domestic assets of the benchmark investment universe. The analysis can be viewed from two different perspectives. First, the investor could be a private investor who is able to buy the benchmark assets from a benchmark

\footnotetext{
${ }^{14}$ Luttmer(1996) and De Roon et al(2001) motivate the transaction costs as the bid/ask spread when the investor can go long or short in a given asset.

${ }^{15}$ The implicit assumption here is that there are zero trading costs on the risk-free asset.
} 
provider such as MSCI. Second, the investor could be an institutional investor who can form the benchmark assets as trading strategies and is considering an investment into CEF portfolios as a way of accessing international diversification benefits. This second perspective is consistent with the findings of Parwada and Siaw(2014) that institutional investors in U.S. CEF tend not to invest in the same stocks that the CEF holds.

As is common with fund performance studies, my analysis is ex post in nature and captures the in-sample diversification benefits of the CEF over a prior historical period. Harvey and Liu(2017) point out that if the data is stationary, then would expect the in-sample performance would persist out-of-sample at least to some degree. This issue is a greater problem for unconstrained sample mean-variance portfolios which tend to be hugely overoptimistic of out-of-sample performance (Kan and Smith(2008), DeMiguel et al(2009)). This problem is greatly reduced when imposing no short selling constraints (Jagannathan and $\mathrm{Ma}(2003))$, as I do in most of my empirical tests.

My sample of CEF includes U.K. CEF with an international equity objective between January 1993 and December 2016. I identify my sample of funds from Morningstar Direct using the Association of Investment Companies (AIC) sector classifications. I select the primary share classification of each fund. I group all funds into one of six investment sectors as:

1. Global - this sector includes funds in the Global High Income, Global, Global Equity and Income, and Global Smaller Companies sectors.

2. Europe - this sector includes funds in the Europe and European Smaller Companies sectors.

3. Asia Pacific - this sector includes funds in the Asia Pacific excluding Japan, Asia Pacific including Japan, Japan, and Japan Smaller Companies sectors. 
4. North America - this sector includes funds in the North America and North America Smaller Companies sectors.

5. Emerging Markets - this sector includes funds in the Global Emerging Markets, European Emerging Markets, and Latin America sectors.

6. Country Specialists - this sector includes funds in the country specialists from the Far East, Europe, and Latin America sectors.

There are 58 Global funds, 16 Europe funds, 35 Asia Pacific funds, 11 North America funds, 22 Emerging Markets funds, and 30 Country funds. I collect the stock returns of each fund between January 1993 and December 2016 from Morningstar. I use the one-month Treasury Bill return as the risk-free asset, collected from London Share Price Database (LSPD) provided by London Business School and Thomson Financial Datastream. I form six equal weighted (EW) portfolios of funds sorted on the basis of the six investment sectors. I calculate the monthly portfolio returns for each investment sector ${ }^{16}$ as the mean monthly returns of all funds within a given sector. Since my sample includes dead funds, the use of sector portfolios minimizes the impact of any survivorship bias or look-ahead bias (Brown, Goetzmann, Ibbotson and Ross(1992), Carhart, Carpenter, Lynch and Musto(2002)) as even funds with a few return observations are included in the portfolios ${ }^{17}$.

I also select my sample of international equity ETF from Morningstar Direct. I identify all ETF with an international equity objective with the primary share class that trades in the U.K. with a base currency in £s. I collect the stock returns for each ETF from

${ }^{16}$ Different characteristics could be used to group funds into portfolios such as investment style. The investment sector of the funds is a common way of classifying funds by Morningstar and AIC. Since I am focusing on the diversification benefits of the funds, group funds by geographical region seems a sensible way to proceed.

${ }^{17}$ Using individual CEF would be more subject to survivorship and look-ahead bias. 
Morningstar Direct. I allocate each ETF to the same six sectors as used above. I combine the Emerging Market and Country sectors together to get a reasonable number of funds. There are 9 funds in the Global sector, 19 funds in the Europe sector, 12 funds in the Asia Pacific sector, 12 funds in the North America sector, and 10 funds in the EM/Country sector. I form equal weighted monthly portfolio returns for each of the five sectors. The sample period for the ETF portfolios is January 2008 and December 2016 so that there are reasonable number of ETF within the sample of funds.

\section{B) Domestic Assets}

I use three groups of domestic assets to capture the investment opportunity set of U.K. stock returns. Using different benchmark investment universes allows us to examine whether any diversification benefits provided by funds is sensitive to the benchmark investment universe used. Details on how the benchmark assets are formed are included in the Appendix. Each benchmark investment universe contains the one-month U.K. Treasury Bill. The first benchmark universe is the monthly excess return on the value weighted U.K. market index (Market). The second benchmark universe includes the excess returns of six size/BM portfolios used in the formation of the SMB and HML factors in the Fama and French(1993) model. The third benchmark investment universe includes the excess returns of six size/momentum portfolios used in the formation of the WML factor in the Carhart(1997) as in Fama and French(2012). The six size/BM portfolios are formed along size (Small and Big) and BM ratio (Growth, Neutral, and Value). The six size/momentum portfolios are formed along size (Small and Big) and momentum (Losers, Neutral, and Winners) ${ }^{18}$.

${ }^{18}$ The use of domestic assets is selected to examine the diversification benefits provided by the international equity CEF and ETF. An interesting extension would be to use international assets as the benchmark investment universe such as global size/BM portfolios or size/momentum portfolios to examine the performance benefits of CEF and ETF. I do not 
Panels A and B of Table 1 report summary statistics of the domestic assets (panel A) and the CEF portfolios (panel B) between January 1993 and December 2016. The summary statistics include the mean, standard deviation, minimum, and maximum monthly excess returns (\%). Panel $\mathrm{C}$ reports the summary statistics for the five ETF portfolios between January 2008 and December 2016.

Table 1 here

Panel A of Table 1 shows that the average excess returns of the size/BM portfolios range between $0.296 \%$ (Small/Growth) and $0.610 \%$ (Small/Value). There is a value effect in the mean excess returns for both Small and Big companies in that the Value portfolio has a higher mean excess return than the Growth portfolio. The value effect is stronger in smaller companies, which is similar to Fama and French(2012). The size effect is more marginal in the size/BM portfolios

There is a much wider spread in the mean excess returns of the size/momentum portfolios in panel A of Table 1 compared to the size/BM portfolios. The average excess returns of the size/momentum portfolios range between $-0.066 \%$ (Big/Losers) and $1.082 \%$ (Small/Winners). There is a strong momentum effect in mean excess returns for both Small and Big companies, where the average excess returns of the Winners portfolio is a lot higher than the Losers portfolio. The momentum effect is stronger in smaller companies. There is a size effect in the Winners portfolios, where the average excess return of the Small portfolio is a lot higher than the Big portfolio.

pursue this issue here and focus on the diversification benefits relative to a domestic benchmark investment universe. 
Panel B of Table 1 shows that the mean excess returns of the CEF portfolios ranges between $0.534 \%$ (Global) and $0.840 \%$ (North America). The Global portfolio has the lowest volatility across the CEF portfolios. The international equity CEF portfolios tend to be more volatile than the benchmark assets, excluding the Global portfolio. In unreported tests, the CEF portfolios are highly correlated with the domestic market index with the correlations ranging between 0.624 (North America) and 0.905 (Global). The high correlations between the market index and CEF portfolios is due to using CEF stock returns, which are affected by local factors in addition to foreign markets and currency risk. These correlations are consistent with Bodurtha et al(1995), Lee and Hong(2002), and Patro(2001) among others.

Panel $\mathrm{C}$ of Table 1 shows that the mean excess returns of the ETF portfolios range between $-0.062 \%$ (Europe) and $0.828 \%$ (North America). The North America sector also has the lowest volatility. The EM/Country sector has a substantially higher volatility than the other sectors. As with the CEF portfolios, the ETF portfolios are highly correlated with the market index. The correlations with the market index range between $0.520 \%$ (Asia Pacific) and $0.886 \%$ (Global). This correlation again stems from the use of ETF stock returns and is consistent with Cao et al(2017).

\section{Empirical Results}

I begin my empirical analysis by considering the diversification benefits of the CEF portfolios using both unconstrained portfolio strategies and constrained portfolio strategies relative to the three benchmark investment universes. Table 2 reports summary statistics of the posterior distribution of the DCER measure for the unconstrained portfolio strategies (panels A to C) and the constrained portfolio strategies (panels D to F). The table includes the mean, standard deviation, fifth percentile $(5 \%)$, tenth percentile $(10 \%)$, and the median of the posterior distribution of the DCER measure. Table 3 reports the mean of the posterior 
distribution of the corresponding optimal portfolio weights from the unconstrained portfolio strategies (panels A to C) and constrained portfolio strategies (panels D to F).

Table 2 here

Table 3 here

Panels $\mathrm{A}$ to $\mathrm{C}$ of Table 2 show that the $\mathrm{CEF}$ portfolios deliver significant diversification benefits relative to all three benchmark investment universes for the unconstrained portfolio strategies. This finding holds for all levels of risk aversion. The mean DCER measures are large in economic terms and all are significant at the 5\% percentile. The optimal mean portfolio weights in panels $\mathrm{A}$ to $\mathrm{C}$ in Table 3 involve large long and short positions. Extreme weights in unconstrained mean-variance portfolios is common (Michaud(1989)). There are large long positions in the Global, North America, and Country sectors across all three benchmark investment universes. There are large short positions in the EM sector. The significant diversification benefits for the unconstrained mean-variance strategies are not attainable for a long-only investor. Even where investors can short sell, the costs of short selling could eliminate the diversification benefits (Fama and French(2015)).

Panels D to F in Table 2 show that there is a sharp drop in the mean and volatility of the DCER measure when there are no short selling constraints. This pattern is consistent with Wang(1998) and Li et al(2003) ${ }^{19}$. The drop in the volatility of the DCER measures is due to

${ }^{19}$ Basak et al(2002) find that the standard error of their mean-variance inefficiency measure increases when there are no short selling constraints. They point out that this result arises because of the linear approximation using the delta method, which becomes more unreliable when there are no short selling constraints. 
the lower estimation risk for sample mean-variance portfolios due to no short selling constraints (Frost and Savarino(1988), Jagannathan and Ma(2003)). However with no short selling constraints, there is a large impact on the magnitude of the diversification benefits provided by CEF portfolios. When the benchmark investment universe includes the market index, in panel D of Table 2, CEF portfolios continue to provide significant diversification benefits. The mean DCER measures are large in economic terms and significant at the 5\% percentile. The mean portfolio weights in panel $\mathrm{D}$ of Table 3 show that there is little exposure to the market index in the optimal portfolios. The dominant weights are in the CEF portfolios, especially with the North America, Europe, and Country sectors. The pattern in mean weights confirms the significant diversification benefits of CEF portfolios when the benchmark investment universe includes the market index.

When the benchmark investment universe includes the size/BM portfolios, no short selling constraints leads to a substantial reduction in the diversification benefits of the CEF portfolios. The mean DCER measures are on the borderline of statistical significance at the $10 \%$ percentile. It is only when $\gamma=1$, where the mean DCER measure is reasonably large. The mean portfolio weights in panel $\mathrm{E}$ of Table 3 confirm that when $\gamma=1$, the CEF portfolios have the dominant weights in the optimal portfolios. When $\gamma=5$, there is more of an even split between the benchmark assets and the CEF portfolios, with a greater weight on Treasury Bills.

When the benchmark investment universe includes the size/momentum portfolios, no short selling constraints eliminate all the diversification benefits of the CEF portfolios. The mean DCER measures are tiny and none are significant at the $5 \%$ or $10 \%$ percentiles. The mean portfolio weights in panel $\mathrm{F}$ of Table 3 confirms the tiny diversification benefits of the CEF portfolios as the dominant weights in the optimal portfolios are in the benchmark assets. 
This result is driven by the large mean weight on the SW portfolio, which is at least 0.672 and above.

Tables 2 and 3 show that the CEF portfolios provide significant diversification benefits when investors can short sell. Imposing no short selling constraints substantially reduces the diversification benefits of CEF portfolios, and eliminates the diversification benefits when the benchmark investment universe includes the size/momentum portfolios. The diversification benefits of the CEF portfolios when the benchmark investment universe includes the market index is similar to Fletcher and Marshall(2005) who use international equity U.K. OEF.

I conduct a couple of robustness tests of the results in Tables 2 and 3. I first consider the use of a different market index. I use the Financial Times All Share ${ }^{20}$ (FTA) index (collected from LSPD) as the market index and repeat the tests in Tables 2 and 3. The results are the same as in Tables 2 and 3 and so are robust to using a different market index. The second test is to restrict the benchmark universe to the Big portfolios in the size/BM and size/momentum portfolios. Fama and French(2008) and Lewellen(2015) find that capital market anomalies are often stronger in smaller companies. Likewise investors might be restricted to investing in the largest stocks in a given market ${ }^{21}$. I repeat the tests in Tables 2 and 3 for the constrained portfolio strategies where the benchmark investment universes include the Big portfolios of the size/BM and size/momentum portfolios. Table 4 reports the corresponding results. Panels A and B report the summary statistics of the posterior

${ }^{20}$ The FTA index is a value weighted index of the largest companies on the London Stock Exchange. As at December 2016, there were 635 companies in the index according to LSPD. ${ }^{21}$ Gregory, Tharyan and Christidis(2013) point out from informal conversations that large international investors are often restricted to the largest 100 U.K. stocks. 
distribution of the DCER measure and panels $\mathrm{C}$ and D report the mean portfolio weights of the optimal portfolios.

Table 4 here

Panel A of Table 4 shows that CEF portfolios now deliver significant diversification benefits when the benchmark investment universe includes the Big size/BM portfolios. The mean DCER measures are large in economic terms and all are significant at the 5\% percentile. The mean DCER measures are higher than in panel E of Table 2, confirming the larger diversification benefits of the CEF portfolios when investors are restricted to the largest stocks. The mean portfolio weights in panel $\mathrm{C}$ of Table 4 show that the exposure to benchmark assets in the optimal portfolios are relatively small, with the sum of mean weights being below 0.18. The dominant weights in the CEF portfolios are in the North America, Europe, and Country CEF portfolios.

When the benchmark investment universe includes the Big size/momentum portfolios, there is a large increase in the mean DCER measures compared to panel F of Table 2, especially when $\gamma=1$ and 3. However the mean DCER measures are on the borderline of statistical significance at the $10 \%$ percentile when $\gamma=1$ and 3 . When $\gamma=1$, the dominant mean weights are in the CEF portfolios, which comprises the bulk of the optimal portfolios. In contrast, when $\gamma=5$, the sum of mean weights in the benchmark assets is larger than the CEF portfolios. Table 4 provides some support that the diversification benefits of CEF portfolios is larger when investors are restricted to the largest stocks.

The next issue I examine is the impact that higher trading costs on the benchmark assets has on the diversification benefits of the CEF portfolios. I repeat the analysis in Tables 2 and 3 for the constrained portfolio strategies but this time impose trading costs of 50 basis 
points on the benchmark assets. Since the CEF portfolios already provide significant diversification benefits when the benchmark investment universe includes the market index, I only run the tests for when the benchmark investment universe includes the size/BM portfolios and the size/momentum portfolios. Table 5 reports summary statistics of the posterior distribution of the DCER measures (panels A and B) and the mean portfolio weights (panels $\mathrm{C}$ and D) for the constrained portfolio strategies. In unreported tests, I also repeat the tests using trading costs of 10 basis points on the size/BM portfolios.

\section{Table 5 here}

Table 5 shows that adjusting for higher trading costs in the benchmark assets has a dramatic effect on the diversification benefits of the CEF portfolios and the mean optimal portfolio weights. This result holds for both benchmark investment universes. When the benchmark investment universe includes the size/BM portfolios, the mean DCER measures are large in economic terms and all are significant at the 5\% percentile. The mean DCER measures in panel A of Table 5 are at least 2.5 times greater than in panel $\mathrm{E}$ of Table 2 . The pattern of the mean weights in the optimal portfolios in panel $\mathrm{C}$ of Table 5 is consistent with the diversification benefits of the CEF portfolios. There is no exposure to the benchmark assets. The dominant mean weights are in the North America, Europe, and Country sectors. Using lower trading costs of 10 basis points on the benchmark assets reduces the magnitude of the diversification benefits of the CEF portfolios but the benefits remain significant.

When the benchmark investment universe includes the size/momentum portfolios, the CEF portfolios deliver significant diversification benefits after adjusting for higher trading costs in the benchmark assets. The increase in the magnitude of the diversification benefits is substantial compared to panel F of Table 2. The mean DCER measures are at least seven 
times larger than in panel $\mathrm{F}$ of Table 2. There is also a dramatic effect on the mean portfolio weights in panel $\mathrm{D}$ of Table 5 compared to panel $\mathrm{F}$ of Table 3. There is a substantial reduction in the mean weight of the SW portfolio in the optimal portfolio. The dominant mean weights are now in the CEF portfolios, with the largest exposures on the North America, Europe, and Country sectors.

Table 5 shows that the CEF portfolios deliver substantial diversification benefits when adjusting for higher trading costs on the benchmark assets. These significant diversification benefits are driven by the North America, Europe, and Country sectors. The impact of adjusting for trading costs is similar to other applications such as De Roon et al(2001) in examining the diversification benefits in emerging markets and De Roon and Szymanowska(2012) in examining the ability of asset pricing models in capturing the timeseries predictability in stock returns.

The final issue I examine is to compare the diversification benefits provided by international equity CEF portfolios and international equity ETF portfolios between January 2008 and December 2016. This comparison is of interest as CEF are predominantly actively managed and ETF are usually passively managed. I repeat the tests of Tables 2 and 3 adding only the CEF portfolios, adding only the ETF portfolios, and adding both the CEF and ETF portfolios to the different benchmark investment universes. Table 6 reports the summary statistics of the posterior distribution of the DCER measures for the constrained portfolio strategies. To conserve space, I do not report the mean portfolio weights of the optimal portfolios but will discuss in the text.

Table 6 here 
Panel A of Table 6 shows that both international equity CEF and ETF portfolios provide significant diversification benefits in the presence of no short selling constraints when the benchmark investment universe is the market index. The mean DCER measures of adding either the CEF portfolios or the ETF portfolios to the benchmark universe are large in economic terms and all are significant at the 5\% percentile. The mean DCER measures in panel A of Table 6 are more volatile than in panel D of Table 2. This result stems from the fact that the number of observations is smaller in Table 6 and is consistent with Wang(1998). The higher volatility of the DCER measure will make it more difficult to find statistical significance. The interesting result is that the magnitude of the diversification benefits of the CEF portfolios is larger in the most recent sample period compared to the whole sample period.

In both cases of adding the CEF portfolios or the ETF portfolios to the benchmark investment universe, the mean weight on the market index in the optimal portfolios is small and less than 0.038. There is a positive mean weight on each CEF portfolio, except for the EM sector. The dominant mean weights in the CEF portfolios are on the North America, Asia Pacific, and Global sectors. The pattern in mean weights differs for the ETF portfolios. The mean weights in the optimal portfolios are lot more heavily loaded on the North America ETF portfolio, with a mean weight in excess of 0.62 .

When the CEF and ETF portfolios are both added to the benchmark investment universe in panel A of Table 6, there is again a significant increase in CER performance across all levels of risk aversion. The mean DCER measures are economically large and significant at the $5 \%$ percentile. In unreported tests, I examine the incremental CER performance of adding the ETF portfolios to the benchmark assets and CEF portfolios, and of adding the CEF portfolios to the benchmark assets and ETF portfolios. The challenge with 
these tests is that although the mean DCER measures are often large, the DCER measures are highly volatile and skewed, which makes it difficult to find statistical significance.

The pattern in the mean weights of the optimal portfolios show that both sets of portfolios are important in delivering the diversification benefits and no one group of funds is redundant in the presence of the other group of funds. When $\gamma=1$, the sum of the mean weights on the CEF portfolios is larger than the ETF portfolios $(0.596 \mathrm{v} 0.395)$. For $\gamma=3$ and 5, the sum of mean weights on the ETF portfolios is larger than the CEF portfolios, even with a smaller number of portfolios. The dominant weights are on the two North America sector portfolios. The mean weight on the CEF North America portfolio ranges between $0.158(\gamma=5)$ and $0.400(\gamma=1)$. In contrast, the mean weight on the ETF North America portfolio ranges between $0.325(\gamma=1)$ and $0.460(\gamma=5)$. These mean weights suggest that both North America portfolios are important. The pattern between risk aversion and the mean weights might suggest that with higher risk aversion, investors prefer the more passively managed ETF.

When the benchmark investment universe includes the size/BM portfolios, panel B of Table 6 shows that neither the CEF or ETF portfolios separately provide significant diversification benefits. None of the mean DCER measures are significant at the 5\% or $10 \%$ percentiles. The magnitude of the mean DCER measures are similar to panel E of Table 2. It is only when the CEF and ETF portfolios are added together, that there are some significant diversification benefits. The mean DCER measures are large in economic terms and on the borderline of statistical significance at the $10 \%$ percentile. The optimal portfolios underlying the increase in CER performance are concentrated in the CEF and ETF portfolios and not in the benchmark assets. As with when the benchmark universe includes the market index, the dominant weights are in the CEF and ETF North America portfolios, with a similar relation 
between risk aversion and the mean weights. The combined mean weights of the CEF and ETF North America portfolios exceeds 0.48.

When the benchmark investment universe includes the size/momentum portfolios, panel $\mathrm{C}$ of Table 6 shows that there is some evidence of both CEF and ETF portfolios providing significant diversification benefits. The mean DCER measures are large in economic terms and on the borderline of statistical significance at the $10 \%$ percentile, when $\gamma$ $=3$ and 5. The magnitude of the mean DCER measures for the CEF portfolios is considerably larger than in panel $\mathrm{F}$ of Table 2. This result again confirms that the diversification benefits, in terms of higher CER performance, provided by CEF portfolios is actually higher in the most recent subperiod.

When the CEF and ETF portfolios are added together there are substantial diversification benefits. The mean DCER measures are large in economic terms and significant at the $5 \%$ percentile when $\gamma=3$ and 5 and at the $10 \%$ percentile when $\gamma=1$. The dominant weights in the optimal portfolios are in the CEF and ETF portfolios with only a small exposure to the size/momentum portfolios. Again it is the North America portfolios that are driving this performance. The combined mean weight on the CEF and ETF North America portfolios exceeds 0.56 .

The results in Table 6 and the mean weights in the optimal portfolios suggest that both the CEF and ETF portfolios are necessary to maximize the diversification benefits. This result is consistent with Cao et al(2017). The significant diversification benefits are driven by the North America sector portfolios with more (less) risk averse investors favouring a greater (lower) mean weight on the ETF (CEF) North America portfolio. Repeating the tests in Table 6 adjusting for the higher trading costs on the benchmark assets, strengthens the findings in Table 6. The diversification benefits are highly significant when the CEF and 
ETF portfolios are added together. The pattern in mean weights of the optimal portfolios is likewise similar.

\section{Conclusion}

This study uses the Bayesian approach of Wang(1998) to examine the diversification benefits provided by international equity closed-end funds and also to compare with ETF portfolios. There are three main findings from my study. First, no short selling constraints have a dramatic impact on the diversification benefits provided by international equity CEF portfolios. There is a substantial reduction in the mean DCER measures in the presence of no short selling constraints. No short selling constraints eliminate all of the diversification benefits when the benchmark investment universe includes the size/momentum portfolios. It is only when the benchmark investment universe includes the market index that the CEF portfolios still provide significant diversification benefits at the $5 \%$ percentile. If we restrict the benchmark assets to only include the Big stock portfolios, the diversification benefits of the CEF portfolios increases and becomes significant for the Big size/BM benchmark universe. The magnitude of the diversification benefits provided by CEF portfolios has increased in the recent January 2008 and December 2016 subperiod. The finding that short selling constraints hurts the mean-variance performance of the trading strategies is similar to other studies such as De Roon et al(2001), Li et al(2003), and Briere and Szafarz(2017).

Second, adjusting for higher trading costs in the benchmark assets has a dramatic effect on the diversification benefits provided by CEF portfolios and the corresponding optimal portfolio weights. The relative impact is greatest for the size/momentum portfolios. The CEF portfolios now provide significant diversification benefits in the presence of no short selling constraints across all benchmark investment universes. The optimal portfolios are now heavily loaded on the CEF portfolios, especially the North America, Europe, and Country sectors. The importance of adjusting for trading costs is consistent in other asset 
pricing applications with Luttmer(1996), De Roon et al(2001), and De Roon and Szymanowska(2012).

Third, adding the CEF and ETF portfolios together provides the strongest support for significant diversification benefits in the January 2008 and December 2016 subperiod. The mean DCER measures are economically large and often statistically significant. The mean weights in the optimal portfolios suggest that neither group of funds is redundant in the presence of the other groups of funds. The North America sector portfolios drive the significant diversification benefits. At lower (higher) risk aversion levels, the mean weight in the CEF (ETF) portfolio increases (decreases). This result suggests that the CEF and ETF portfolios are capturing different aspects of international investment opportunities in international equity markets. The importance of both CEF and ETF is consistent with Cao et $\operatorname{al}(2017)$.

My study suggests that international equity CEF provide significant diversification benefits in the presence of no short selling constraints once we control for higher trading costs in the benchmark assets. Likewise both CEF and ETF portfolios together provide significant diversification benefits and so are useful investment vehicles for investors who wish to gain access to foreign equity markets without directly investing in these markets. My study examines the diversification benefits of the CEF portfolios across the whole sample period. An interesting extension would be to examine whether the diversification benefits provided by funds varies across different states of the world, possibly using the regime switching method of Ang and Bekaert(2004). My benchmark investment universes include only U.K assets. An interesting extension would be to examine the mean-variance performance provided by $\mathrm{CEF}$ when the benchmark investment universe includes foreign assets. Likewise, we could examine the diversification benefits of CEF by using different fund characteristics to form the CEF portfolios. I leave these issues to future research. 


\section{Appendix}

\section{Domestic Assets}

I construct the market index using a similar approach to Dimson and Marsh(2001). At the start of each year between 1993 and 2016, I construct a value weighted portfolio of all stocks on LSPD by their market value at the start of the year. I calculate buy and hold monthly returns during the next year. I exclude companies with a zero market value. I make a number of corrections and exclusions to the portfolio returns which I follow through the formation of all the benchmark assets. Where a security has missing return observations during the year or month, I assign a zero return to the missing values as in Liu and Strong(2008). I correct for the delisting bias of Shumway(1997) by following the approach of Dimson, Nagel and Quigley(2003). A $-100 \%$ return is assigned to the death event date on LSPD where the LSPD code indicates that the death is valueless. I exclude closed-end funds, foreign companies, and secondary shares using data from the LSPD archive file.

To form the six size/BM portfolios, I use a similar approach to Fama and French(2012). At the start of July year between 1992 and 2016, all stocks on LSPD are ranked separately by their market value at the end of June and by their BM ratio from the prior calendar year. The BM ratio is calculated using the book value of equity at the fiscal year-end (WC03501) during the previous calendar year from Worldscope (provided by Thompson Financial) and the year-end market value. Two size groups (Small and Big) are formed using a breakpoint of $90 \%$ by aggregate market capitalization where the Small stocks are the companies with smallest $10 \%$ by market value and the Big stocks are the companies with the largest $90 \%$ by market value. Three BM groups (Growth, Neutral, and Value) are formed using break points of the $30^{\text {th }}$ and $70^{\text {th }}$ percentiles of the BM ratios of Big stocks. Six portfolios of securities are then constructed at the intersection of the size and BM groups (SG, $\mathrm{SN}, \mathrm{SV}, \mathrm{BG}, \mathrm{BN}, \mathrm{BV})$. The monthly buy and hold return for the six portfolios are then 
calculated during the next 12 months. The initial weights are set equal to the market value weights at the end of June. Companies with a zero market value, and negative book values are excluded.

I form the six size/momentum portfolios using a similar approach to Fama and French(2012). At the start of each month between January 1993 and December 2016, all stocks on LSPD are ranked separately by their market value at the end of the previous month and on the basis of their cumulative return from months -12 to -2 . Two size groups (Small and Big) are formed as in the case of the size/BM portfolios. Three past return groups (Losers, Neutral, and Winners) are formed using break points of the $30^{\text {th }}$ and $60^{\text {th }}$ percentiles of the past returns of Big stocks. Six portfolios of securities are then constructed at the intersection of the size and momentum groups ( $\mathrm{SL}, \mathrm{SN}, \mathrm{SW}, \mathrm{BL}, \mathrm{BN}, \mathrm{BW})$. The value weighted return for the six portfolios are then calculated during the next month. Companies with a zero market value, and less than 12 return observations during the past year are excluded from the portfolios. 
Table 1 Summary Statistics of Domestic Assets and Investment Sector Fund Portfolios

\begin{tabular}{|c|c|c|c|c|}
\hline Panel A: & & Standard & & \\
\hline Benchmark & Mean & Deviation & Minimum & Maximum \\
\hline Market & 0.405 & 3.687 & -13.058 & 9.774 \\
\hline SG & 0.296 & 5.262 & -23.793 & 20.586 \\
\hline SN & 0.540 & 4.607 & -21.419 & 16.660 \\
\hline SV & 0.610 & 4.478 & -24.437 & 17.269 \\
\hline BG & 0.371 & 3.699 & -10.975 & 11.958 \\
\hline $\mathrm{BN}$ & 0.443 & 4.146 & -18.362 & 10.438 \\
\hline BV & 0.479 & 4.649 & -17.132 & 14.923 \\
\hline SL & -0.022 & 6.152 & -27.964 & 31.642 \\
\hline $\mathrm{SN}$ & 0.563 & 4.480 & -24.777 & 13.351 \\
\hline SW & 1.082 & 4.734 & -22.407 & 13.639 \\
\hline BL & -0.066 & 5.954 & -29.595 & 30.892 \\
\hline $\mathrm{BN}$ & 0.579 & 3.776 & -12.750 & 10.142 \\
\hline BW & 0.623 & 4.343 & -19.402 & 14.788 \\
\hline Panel B: & & Standard & & \\
\hline CEF & Mean & Deviation & Minimum & Maximum \\
\hline Global & 0.534 & 4.097 & -20.168 & 15.775 \\
\hline Europe & 0.809 & 6.041 & -23.025 & 22.172 \\
\hline Asia Pacific & 0.574 & 6.348 & -22.065 & 26.290 \\
\hline North America & 0.840 & 6.577 & -22.052 & 48.935 \\
\hline EM & 0.640 & 7.123 & -40.368 & 19.230 \\
\hline Country & 0.740 & 6.140 & -30.548 & 22.147 \\
\hline Panel C: & & Standard & & \\
\hline ETF & Mean & Deviation & Minimum & Maximum \\
\hline Global & 0.582 & 4.022 & -11.498 & 9.391 \\
\hline Europe & -0.062 & 4.984 & -16.589 & 19.957 \\
\hline Asia Pacific & 0.447 & 4.965 & -13.308 & 11.800 \\
\hline North America & 0.828 & 3.995 & -9.446 & 9.409 \\
\hline EM/Country & 0.101 & 7.440 & -20.778 & 22.022 \\
\hline
\end{tabular}

The table reports summary statistics of the monthly excess returns of U.K. benchmark assets, six portfolios of U.K. international equity CEF sorted by investment sector, and five portfolios of international equity ETF sorted by investment sector. The summary statistics include the mean, standard deviation, minimum, and maximum monthly excess returns (\%). The sample period for the benchmark assets and CEF portfolios is January 1993 and December 2016. The sample period for the ETF portfolios is January 2008 and December 2016. The benchmark assets include the value weighted U.K. market index, six size/BM portfolios (SG to BV), and six size/momentum portfolios (SL to BW). The international CEF and ETF portfolios are sorted by international equity sector as Global, Europe, Asia Pacific, North America, Emerging Markets (EM), and Country. 
Table 2 Diversification Benefits of International Equity CEF Portfolios

\begin{tabular}{|c|c|c|c|c|c|}
\hline Panel A: & & Standard & & & \\
\hline Market & Mean & Deviation & $5 \%$ & $10 \%$ & Median \\
\hline$\gamma=1$ & 1.788 & 0.967 & 0.508 & 0.685 & 1.632 \\
\hline$\gamma=3$ & 0.596 & 0.322 & 0.169 & 0.228 & 0.544 \\
\hline$\gamma=5$ & 0.357 & 0.193 & 0.101 & 0.137 & 0.326 \\
\hline Panel B: & & Standard & & & \\
\hline Size/BM & Mean & Deviation & $5 \%$ & $10 \%$ & Median \\
\hline$\gamma=1$ & 1.925 & 1.031 & 0.597 & 0.754 & 1.710 \\
\hline$\gamma=3$ & 0.641 & 0.343 & 0.199 & 0.251 & 0.570 \\
\hline$\gamma=5$ & 0.385 & 0.206 & 0.119 & 0.150 & 0.342 \\
\hline Panel C: & & Standard & & & \\
\hline Size/Momentum & Mean & Deviation & $5 \%$ & $10 \%$ & Median \\
\hline$\gamma=1$ & 1.917 & 1.060 & 0.573 & 0.719 & 1.699 \\
\hline$\gamma=3$ & 0.639 & 0.353 & 0.191 & 0.239 & 0.566 \\
\hline$\gamma=5$ & 0.383 & 0.212 & 0.114 & 0.143 & 0.339 \\
\hline Panel D: & & Standard & & & \\
\hline Market & Mean & Deviation & $5 \%$ & $10 \%$ & Median \\
\hline$\gamma=1$ & 0.487 & 0.217 & 0.131 & 0.216 & 0.483 \\
\hline$\gamma=3$ & 0.284 & 0.176 & 0.038 & 0.067 & 0.265 \\
\hline$\gamma=5$ & 0.174 & 0.118 & 0.019 & 0.036 & 0.159 \\
\hline Panel E: & & Standard & & & \\
\hline Size/BM & Mean & Deviation & $5 \%$ & $10 \%$ & Median \\
\hline$\gamma=1$ & 0.263 & 0.202 & 0 & 0.008 & 0.242 \\
\hline$\gamma=3$ & 0.147 & 0.144 & 0 & 0.004 & 0.108 \\
\hline$\gamma=5$ & 0.091 & 0.097 & 0 & 0.002 & 0.065 \\
\hline Panel F: & & Standard & & & \\
\hline Size/Momentum & Mean & Deviation & $5 \%$ & $10 \%$ & Median \\
\hline$\gamma=1$ & 0.047 & 0.101 & 0 & 0 & 0 \\
\hline$\gamma=3$ & 0.029 & 0.060 & 0 & 0 & 0.001 \\
\hline$\gamma=5$ & 0.022 & 0.043 & 0 & 0 & 0.002 \\
\hline
\end{tabular}

The table reports summary statistics of the posterior distribution of the DCER (\%) measure of the diversification benefits of international equity CEF portfolios between January 1993 and December 2016. The DCER measure is the increase in CER performance of adding six international equity CEF portfolios to a benchmark investment universe. The international CEF portfolios are sorted by international equity sector as Global, Europe, Asia Pacific, North America, Emerging Markets, and Country. The summary statistics include the mean, standard deviation, fifth percentile (5\%), tenth percentile $(10 \%)$, and the median of the posterior distribution of the DCER measure. There are three benchmark investment universes. Each universe includes the one-month Treasury Bill return. The first benchmark universe is the excess returns on the market index. The second benchmark universe is the excess returns on six size/BM portfolios. The third benchmark universe is the excess returns on six size/momentum portfolios. I set the risk aversion $(\gamma)$ level to 1,3 , and 5. Panels A to $\mathrm{C}$ report the results for the unconstrained portfolio strategies. Panels D to F report the results for the constrained portfolio strategies, where no short selling is allowed in the risky assets and the one-month Treasury Bill. 
Table 3 Mean Portfolio Weights in Constrained Portfolio Strategies: Benchmark Assets and CEF Portfolios

\begin{tabular}{|c|c|c|c|c|c|c|c|c|c|c|c|c|}
\hline $\begin{array}{l}\text { Panel A: } \\
\text { Market }\end{array}$ & Market & Global & Europe & $\begin{array}{r}\text { Asia } \\
\text { Pacific }\end{array}$ & $\begin{array}{r}\text { North } \\
\text { America }\end{array}$ & EM & Country & & & & & \\
\hline$\gamma=1$ & -1.621 & 1.710 & 1.549 & -0.313 & 1.074 & -1.372 & 1.732 & & & & & \\
\hline$\gamma=3$ & -0.540 & 0.570 & 0.516 & -0.104 & 0.358 & -0.457 & 0.577 & & & & & \\
\hline$\gamma=5$ & -0.324 & 0.342 & 0.309 & -0.062 & 0.214 & -0.274 & 0.346 & & & & & \\
\hline $\begin{array}{l}\text { Panel B: } \\
\text { Size/BM }\end{array}$ & SG & $\mathrm{SN}$ & SV & BG & $\mathrm{BN}$ & $\mathrm{BV}$ & Global & Europe & $\begin{array}{r}\text { Asia } \\
\text { Pacific }\end{array}$ & $\begin{array}{r}\text { North } \\
\text { America }\end{array}$ & EM & Country \\
\hline$\gamma=1$ & -8.441 & 6.850 & 1.781 & 2.585 & -1.893 & -1.990 & 0.549 & 2.892 & -0.104 & 1.199 & -1.278 & 1.504 \\
\hline$\gamma=3$ & -2.813 & 2.283 & 0.593 & 0.861 & -0.631 & -0.663 & 0.183 & 0.964 & -0.034 & 0.399 & -0.426 & 0.501 \\
\hline$\gamma=5$ & -1.688 & 1.370 & 0.356 & 0.517 & -0.378 & -0.398 & 0.109 & 0.578 & -0.020 & 0.239 & -0.255 & 0.300 \\
\hline $\begin{array}{l}\text { Panel C: } \\
\text { Size/Momentum }\end{array}$ & SL & $\mathrm{SN}$ & SW & $\mathrm{BL}$ & $\mathrm{BN}$ & BW & Global & Europe & $\begin{array}{r}\text { Asia } \\
\text { Pacific }\end{array}$ & $\begin{array}{r}\text { North } \\
\text { America }\end{array}$ & $\mathrm{EM}$ & Country \\
\hline$\gamma=1$ & -10.227 & 2.646 & 11.833 & -1.143 & 6.598 & -6.455 & 4.463 & -0.566 & -0.441 & 1.410 & -2.107 & 1.838 \\
\hline$\gamma=3$ & -3.409 & 0.882 & 3.944 & -0.381 & 2.199 & -2.151 & 1.487 & -0.188 & -0.147 & 0.470 & -0.702 & 0.612 \\
\hline$\gamma=5$ & -2.045 & 0.529 & 2.366 & -0.228 & 1.319 & -1.291 & 0.892 & -0.113 & -0.088 & 0.282 & -0.421 & 0.367 \\
\hline $\begin{array}{l}\text { Panel D: } \\
\text { Market }\end{array}$ & Market & Global & Europe & $\begin{array}{r}\text { Asia } \\
\text { Pacific }\end{array}$ & $\begin{array}{r}\text { North } \\
\text { America }\end{array}$ & EM & Country & & & & & \\
\hline$\gamma=1$ & 0.004 & 0.007 & 0.313 & 0.048 & 0.368 & 0.060 & 0.190 & & & & & \\
\hline$\gamma=3$ & 0.045 & 0.057 & 0.260 & 0.043 & 0.275 & 0.027 & 0.179 & & & & & \\
\hline$\gamma=5$ & 0.063 & 0.075 & 0.163 & 0.029 & 0.182 & 0.015 & 0.123 & & & & & \\
\hline $\begin{array}{l}\text { Panel E: } \\
\text { Size/BM }\end{array}$ & SG & SN & SV & BG & $\mathrm{BN}$ & BV & Global & Europe & $\begin{array}{r}\text { Asia } \\
\text { Pacific }\end{array}$ & $\begin{array}{r}\text { North } \\
\text { America }\end{array}$ & EM & Country \\
\hline$\gamma=1$ & 0.001 & 0.017 & 0.086 & 0.016 & 0.007 & 0.020 & 0 & 0.266 & 0.049 & 0.319 & 0.049 & 0.161 \\
\hline$\gamma=3$ & 0.001 & 0.042 & 0.169 & 0.058 & 0.024 & 0.040 & 0.004 & 0.189 & 0.038 & 0.213 & 0.018 & 0.134 \\
\hline$\gamma=5$ & 0.000 & 0.039 & 0.164 & 0.074 & 0.028 & 0.036 & 0.011 & 0.113 & 0.025 & 0.141 & 0.009 & 0.090 \\
\hline $\begin{array}{l}\text { Panel F: } \\
\text { Size/Momentum }\end{array}$ & SL & SN & SW & BL & $\mathrm{BN}$ & BW & Global & Europe & $\begin{array}{r}\text { Asia } \\
\text { Pacific }\end{array}$ & $\begin{array}{r}\text { North } \\
\text { America }\end{array}$ & EM & Country \\
\hline$\gamma=1$ & 0 & 0.000 & 0.708 & 0 & 0.012 & 0.007 & 0 & 0.051 & 0.017 & 0.132 & 0.023 & 0.046 \\
\hline$\gamma=3$ & 0 & 0.000 & 0.763 & 0 & 0.052 & 0.017 & 0 & 0.019 & 0.011 & 0.088 & 0.008 & 0.029 \\
\hline$\gamma=5$ & 0 & 0.001 & 0.672 & 0 & 0.105 & 0.025 & 0 & 0.007 & 0.008 & 0.069 & 0.003 & 0.022 \\
\hline
\end{tabular}


The table reports the mean of the posterior distribution of the optimal portfolio weights of adding six international equity CEF portfolios to a benchmark investment universe between January 1993 and December 2016. The international CEF portfolios are sorted by international equity sector as Global, Europe, Asia Pacific, North America, Emerging Markets (EM), and Country. There are three benchmark investment universes. Each universe includes the one-month Treasury Bill return. The first benchmark universe is the excess returns on the market index. The second benchmark universe is the excess returns on six size/BM portfolios. The third benchmark universe is the excess returns on six size/momentum portfolios. I set the risk aversion $(\gamma)$ level to 1, 3, and 5. Panels D to F report the results for the constrained portfolio strategies, where no short selling is allowed in the risky assets and the one-month Treasury Bill. 
Table 4 Diversification Benefits of CEF Portfolios when Benchmark Assets are Restricted to Big stocks: Constrained Portfolio Strategies

\begin{tabular}{|c|c|c|c|c|c|c|c|c|c|}
\hline Panel A: & \multicolumn{6}{|c|}{ Standard } & & & \\
\hline Size/BM & \multicolumn{2}{|c|}{ Mean } & \multicolumn{2}{|c|}{ Deviation } & \multicolumn{2}{|c|}{$5 \%$} & \multicolumn{2}{|c|}{$10 \%$} & Median \\
\hline$\gamma=1$ & \multicolumn{2}{|c|}{0.378} & \multicolumn{2}{|c|}{0.225} & \multicolumn{2}{|c|}{0.020} & \multicolumn{2}{|c|}{0.076} & 0.360 \\
\hline$\gamma=3$ & \multicolumn{2}{|c|}{0.225} & \multicolumn{2}{|c|}{0.169} & \multicolumn{2}{|c|}{0.010} & \multicolumn{2}{|c|}{0.027} & 0.196 \\
\hline$\gamma=5$ & \multicolumn{2}{|c|}{0.142} & \multicolumn{2}{|c|}{0.113} & \multicolumn{2}{|c|}{0.006} & \multicolumn{2}{|c|}{0.016} & 0.118 \\
\hline Panel B: & \multirow{2}{*}{\multicolumn{2}{|c|}{ Mean }} & \multicolumn{2}{|c|}{ Standard } & \multirow{2}{*}{\multicolumn{2}{|c|}{$5 \%$}} & \multirow{2}{*}{\multicolumn{2}{|c|}{$10 \%$}} & \\
\hline Size/Momentum & & & Devic & & & & & & Median \\
\hline$\gamma=1$ & \multicolumn{2}{|c|}{0.258} & \multicolumn{2}{|c|}{$\begin{array}{l}0.214 \\
0.143\end{array}$} & \multicolumn{2}{|c|}{0} & \multicolumn{2}{|c|}{0.001} & 0.227 \\
\hline$\gamma=3$ & \multicolumn{2}{|c|}{0.138} & & & \multicolumn{2}{|c|}{0} & \multicolumn{2}{|c|}{0.001} & 0.091 \\
\hline$\gamma=5$ & \multicolumn{2}{|c|}{0.084} & \multicolumn{2}{|c|}{0.093} & \multicolumn{2}{|c|}{0} & \multicolumn{2}{|c|}{0.000} & 0.054 \\
\hline Panel C: & & & & & & Asia & North & & \\
\hline Size/BM & BG & $\mathrm{BN}$ & BV & Global & Europe & Pacific & America & EM & Country \\
\hline$\gamma=1$ & 0.016 & 0.019 & 0.024 & 0.002 & 0.272 & 0.047 & 0.355 & 0.070 & 0.186 \\
\hline$\gamma=3$ & 0.068 & 0.048 & 0.050 & 0.031 & 0.216 & 0.043 & 0.250 & 0.029 & 0.168 \\
\hline$\gamma=5$ & 0.084 & 0.049 & 0.045 & 0.042 & 0.133 & 0.029 & 0.164 & 0.016 & 0.117 \\
\hline Panel D: & & & & & & Asia & North & & \\
\hline Size/Momentum & $\mathrm{BL}$ & $\mathrm{BN}$ & BW & Global & Europe & Pacific & America & EM & Country \\
\hline$\gamma=1$ & 0 & 0.082 & 0.099 & 0.002 & 0.213 & 0.036 & 0.331 & 0.056 & 0.175 \\
\hline$\gamma=3$ & 0 & 0.233 & 0.181 & 0.005 & 0.144 & 0.025 & 0.208 & 0.020 & 0.137 \\
\hline$\gamma=5$ & 0 & 0.282 & 0.176 & 0.011 & 0.079 & 0.016 & 0.135 & 0.009 & 0.096 \\
\hline
\end{tabular}


The table reports summary statistics of the posterior distribution of the DCER (\%) measure of the diversification benefits of international equity CEF portfolios (panels A and B) and the mean optimal portfolio weights (panels C and D) between January 1993 and December 2016 for constrained portfolio strategies when the benchmark universe is restricted to the largest stocks. The DCER measure is the increase in CER performance of adding six international equity CEF portfolios to a benchmark investment universe. The international CEF portfolios are sorted by international equity sector as Global, Europe, Asia Pacific, North America, Emerging Markets (EM), and Country. The summary statistics include the mean, standard deviation, fifth percentile (5\%), tenth percentile (10\%), and the median of the posterior distribution of the DCER measure. There are two benchmark investment universes. Each universe includes the one-month Treasury Bill return. The first benchmark universe is the excess returns on three Big size/BM portfolios. The second benchmark universe is the excess returns on three Big size/momentum portfolios. I set the risk aversion $(\gamma)$ level to 1, 3, and 5. In the constrained portfolio strategies, no short selling constraints are imposed on the risky assets and the one-month Treasury Bill. 
Table 5 Diversification Benefits of CEF Portfolios when Benchmark Assets have Trading Costs: Constrained Portfolio Strategies

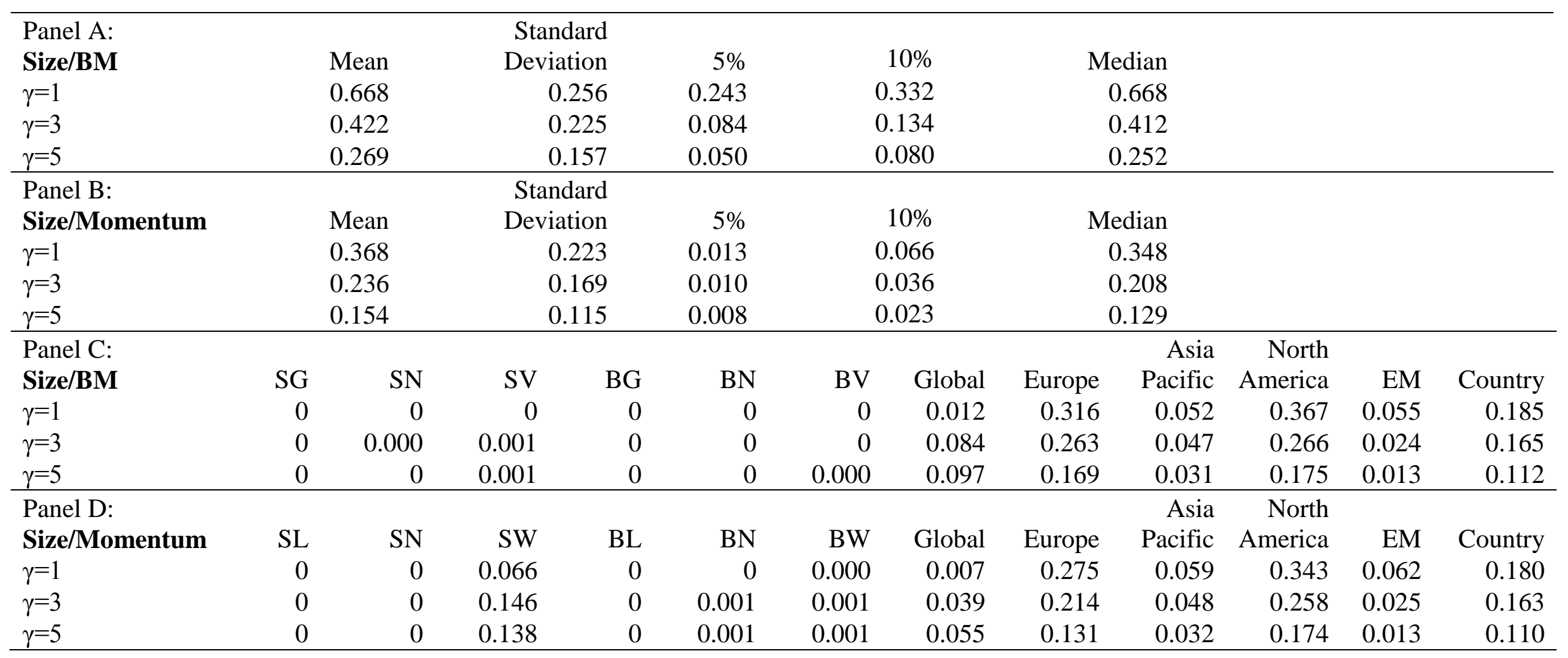


The table reports summary statistics of the posterior distribution of the DCER (\%) measure of the diversification benefits of international equity CEF portfolios (panels A and B) and the mean optimal portfolio weights (panels C and D) between January 1993 and December 2016 for constrained portfolio strategies in the presence of trading costs. The DCER measure is the increase in CER performance of adding six international equity CEF portfolios to a benchmark investment universe. The international CEF portfolios are sorted by international equity sector as Global, Europe, Asia Pacific, North America, Emerging Markets (EM), and Country. The summary statistics include the mean, standard deviation, fifth percentile (5\%), tenth percentile (10\%), and the median of the posterior distribution of the DCER measure. There are two benchmark investment universes. Each universe includes the one-month Treasury Bill return. The first benchmark universe is the excess returns on six size/BM portfolios. The second benchmark universe is the excess returns on six size/momentum portfolios. I set the risk aversion $(\gamma)$ level to 1, 3, and 5. In the constrained portfolio strategies, no short selling constraints are imposed on the risky assets and the one-month Treasury Bill. I set the proportional transaction cost to 50 basis points on the benchmark assets. 
Table 6 Diversification Benefits of International CEF and ETF Portfolios: Constrained Portfolio Strategies

\begin{tabular}{|c|c|c|c|c|c|}
\hline $\begin{array}{l}\text { Panel A: } \\
\text { Market }\end{array}$ & Mean & $\begin{array}{r}\text { Standard } \\
\text { Deviation }\end{array}$ & $5 \%$ & $10 \%$ & Median \\
\hline \multicolumn{6}{|l|}{ CEF } \\
\hline$\gamma=1$ & 0.577 & 0.410 & 0.014 & 0.093 & 0.494 \\
\hline$\gamma=3$ & 0.369 & 0.301 & 0.003 & 0.043 & 0.293 \\
\hline$\gamma=5$ & 0.251 & 0.219 & 0.002 & 0.025 & 0.191 \\
\hline ETF & Mean & Standard Deviation & $5 \%$ & $10 \%$ & Median \\
\hline$\gamma=1$ & 0.415 & 0.252 & 0.005 & 0.064 & 0.400 \\
\hline$\gamma=3$ & 0.357 & 0.238 & 0.005 & 0.045 & 0.340 \\
\hline$\gamma=5$ & 0.291 & 0.216 & 0.006 & 0.032 & 0.253 \\
\hline $\mathrm{CEF}+\mathrm{ETF}$ & Mean & Standard Deviation & $5 \%$ & $10 \%$ & Median \\
\hline$\gamma=1$ & 0.690 & 0.356 & 0.215 & 0.292 & 0.638 \\
\hline$\gamma=3$ & 0.526 & 0.279 & 0.112 & 0.191 & 0.513 \\
\hline$\gamma=5$ & 0.413 & 0.238 & 0.068 & 0.121 & 0.393 \\
\hline \multicolumn{5}{|l|}{ Panel B: } & Median \\
\hline \multicolumn{6}{|l|}{$\mathrm{CEF}$} \\
\hline$\gamma=1$ & 0.299 & 0.351 & 0 & 0 & 0.171 \\
\hline$\gamma=3$ & 0.165 & 0.224 & 0 & 0 & 0.070 \\
\hline$\gamma=5$ & 0.105 & 0.150 & 0 & 0 & 0.042 \\
\hline ETF & Mean & Standard Deviation & $5 \%$ & $10 \%$ & Median \\
\hline$\gamma=1$ & 0.180 & 0.210 & 0 & 0 & 0.107 \\
\hline$\gamma=3$ & 0.161 & 0.186 & 0 & 0 & 0.095 \\
\hline$\gamma=5$ & 0.139 & 0.162 & 0 & 0 & 0.083 \\
\hline $\mathrm{CEF}+\mathrm{ETF}$ & Mean & Standard Deviation & $5 \%$ & $10 \%$ & Median \\
\hline$\gamma=1$ & 0.381 & 0.336 & 0 & 0.001 & 0.319 \\
\hline$\gamma=3$ & 0.272 & 0.242 & 0 & 0.008 & 0.219 \\
\hline$\gamma=5$ & 0.212 & 0.193 & 0 & 0.009 & 0.163 \\
\hline $\begin{array}{l}\text { Panel C: } \\
\text { Size/Momentum }\end{array}$ & Mean & Standard Deviation & $5 \%$ & $10 \%$ & Median \\
\hline \multicolumn{6}{|l|}{$\mathrm{CEF}$} \\
\hline$\gamma=1$ & 0.440 & 0.397 & 0 & 0 & 0.360 \\
\hline$\gamma=3$ & 0.288 & 0.277 & 0 & 0.002 & 0.214 \\
\hline$\gamma=5$ & 0.197 & 0.195 & 0 & 0.003 & 0.141 \\
\hline ETF & Mean & Standard Deviation & $5 \%$ & $10 \%$ & Median \\
\hline$\gamma=1$ & 0.323 & 0.289 & 0 & 0 & 0.287 \\
\hline$\gamma=3$ & 0.304 & 0.252 & 0 & 0.006 & 0.258 \\
\hline$\gamma=5$ & 0.254 & 0.217 & 0 & 0.011 & 0.202 \\
\hline $\mathrm{CEF}+\mathrm{ETF}$ & Mean & Standard Deviation & $5 \%$ & $10 \%$ & Median \\
\hline$\gamma=1$ & 0.544 & 0.379 & 0 & 0.061 & 0.510 \\
\hline$\gamma=3$ & 0.434 & 0.290 & 0.017 & 0.059 & 0.409 \\
\hline$\gamma=5$ & 0.344 & 0.239 & 0.018 & 0.052 & 0.309 \\
\hline
\end{tabular}


The table reports summary statistics of the posterior distribution of the DCER (\%) measure of the diversification benefits of international equity CEF and ETF portfolios between January 2008 and December 2016. The DCER measure is the increase in CER performance of adding either six international equity CEF portfolios, or five international equity ETF portfolios, or adding both the CEF and ETF portfolios (CEF+ETF) to a benchmark investment universe. The international closed-end fund portfolios are sorted by international equity sector as Global, Europe, Asia Pacific, North America, Emerging Markets, and Country. The ETF Portfolios combine the Emerging Markets and Country sectors into one portfolio. The summary statistics include the mean, standard deviation, fifth percentile (5\%), tenth percentile (10\%), and the median of the posterior distribution of the DCER measure. There are three benchmark investment universes. Each universe includes the one-month Treasury Bill return. The first benchmark universe is the excess returns on the market index (panel A). The second benchmark universe is the excess returns on 6 size/BM portfolios (panel B). The third benchmark universe is the excess returns on 6 size/momentum portfolios (panel C). I set the risk aversion $(\gamma)$ level to 1,3 , and 5. The results are reported for the constrained portfolio strategies, where no short selling is allowed in the risky assets or the one-month Treasury Bill. 


\section{References}

Ang, A. and G. Bekaert, 2004, How do regimes affect asset allocation?, Financial Analysts Journal, 60, 86-99.

Aragon, G. and W.E. Ferson, 2008, Portfolio performance evaluation, Foundations and Trends in Finance, 2, 83-190.

Balduzzi, P. and A.W. Lynch, 1999, Transaction costs and predictability: Some utility cost calculations, Journal of Financial Economics, 52, 47-78.

Basak, G., Jagannathan, R. and G. Sun, 2002, A direct test for the mean-variance efficiency of a portfolio, Journal of Economic Dynamics and Control, 26, 1195-1215.

Bekaert, G. and Urias, M.S., 1996, Diversification, integration and emerging market closedend funds, Journal of Finance, 51 835-869.

Berk, J.B. and R. Stanton, 2007, Managerial ability, compensation, and the closed-end fund discount, Journal of Finance, 62, 529-556.

Best, M.J. and R.R. Grauer, 1990, The efficient set mathematics when the mean variance problem is subject to general linear constraints, Journal of Economics and Business, 42, 105120.

Best, M.J. and R.R. Grauer, 2011, Prospect-theory portfolios versus power-utility and meanvariance portfolios, Working Paper, University of Waterloo.

Briere, M., Drut, B, Mignon, V., Oosterlinck, K. and A. Szafarz, 2013, Is the market portfolio efficient? A new test of mean-variance efficiency when all assets are risky, Finance, 34, 7-41. Briere, M. and A. Szafarz, 2017, Factor investing: The rocky road from long-only to longshort, in E. Jurczenko (Ed), Factor Investing, Elsevier, forthcoming.

Bodurtha, J.N., Kim, D. and C.M.C. Lee, 1995, Closed-end country funds and U.S. market sentiment, Review of Financial Studies, 8, 879-918. 
Britten-Jones, M., 1999, The sampling error in estimates of mean-variance efficient portfolio weights, Journal of Finance, 54, 655-671.

Brown, S. J., Goetzmann, W.N., Ibbotson, R. and S.A. Ross, 1992, Survivorship bias in performance studies, Review of Financial Studies, 5, 553-580.

Cao, J, Fu, R. and Y. Jin, 2017, International diversification through iShares and their rivals, Journal of Risk, 19, 25-55.

Carhart, M. M., 1997, Persistence in mutual fund performance. Journal of Finance, 52, 57-82.

Carhart, M.M., Carpenter, J.N., Lynch, A.W. and D.K. Musto, 2002, Mutual fund survivorship, Review of Financial Studies, 15, 1439-1463.

Cherkes, M., 2012, Closed-end funds: A survey, Annual Review of Financial Economics, 4, 431-445.

Cherkes, M., Sagi, J. and R. Stanton, 2009, A liquidity-based theory of closed-end funds, Review of Financial Studies, 22, 257-297.

Chordia, T., 1996, The structure of mutual fund charges, Journal of Financial Economics, 41, 3-39.

DeMiguel, V., Garlappi, L. and R. Uppal, 2009, Optimal versus naïve diversification: How inefficient is the 1/N portfolio strategy?, Review of Financial Studies, 22, 1915-1953.

De Roon, F.A. and P. Karehnke, 2017, Spanning tests for assets with option-like payoffs: the case of hedge funds, Working Paper, University of New South Wales.

De Roon, F.A. and T.E. Nijman, 2001, Testing for mean-variance spanning: A survey, Journal of Empirical Finance, 8, 111-156.

De Roon, F.A., Nijman, T.E. and B.J.M. Werker, 2001, Testing for mean-variance spanning with short sales constraints and transaction costs: The case of emerging markets, Journal of Finance, 56, 721-742. 
De Roon, F.A. and M. Szymanowska, 2012, Asset pricing restrictions on predictability: Frictions matter, Management Science, 58, 1916-1932.

Dimson, P. and P. R. Marsh, 2001, U.K. financial market returns 1955-2000, Journal of Business, 74, 1-31.

Dimson,E. and C. Minio-Paluello, 2002, The closed-end fund discount, Research Monograph, CFA Institute.

Dimson, P., Nagel, S. and G. Quigley, 2003, Capturing the value premium in the U.K. 19552001, Financial Analysts Journal, 5559, 35-45.

Edelen, R.M., 1999, Investor flows and the assessed performance of open-end mutual funds, Journal of Financial Economics, 53, 439-466.

Ehling, P. and Ramos, S.B., 2006, Geographic versus industry diversification: Constraints matter, Journal of Empirical Finance,13, 396-416.

Eiling, E., Gerard, B., Hillion, P. and F. de Roon, 2012, International portfolio diversification: Currency, industry and country effects revisited, Journal of International Money and Finance, 31, 1249-1278.

Elton, E.J., Gruber, M.J., Blake, C.R. and O. Shacher, 2013, Why do closed-end bond funds exist? An additional explanation for the growth in domestic closed-end bond funds, Journal of Financial and Quantitative Analysis, 48, 405-425.

Errunza, V., Hogan, K. and M.W. Hung, 1999, Can the gains from international diversification be achieved without trading abroad?, Journal of Finance, 2075-2107.

Fama, E.F. and K.R. French, 1993, Common risk factors in the returns on stocks and bonds. Journal of Financial Economics 33, 3-56.

Fama, E.F. and K.R. French, 2008, Dissecting anomalies, Journal of Finance, 63, 1653-1678. Fama, E.F. and K.R. French, 2012, Size, value and momentum in international stock returns, Journal of Financial Economics, 105, 457-472. 
Fama, E.F. and K.R. French, 2015, Incremental variables and the investment opportunity set, Journal of Financial Economics, 117, 470-488.

Fama, E.F. and M.C. Jensen, 1983, Agency problems and residual claims, Journal of Law and Economics, 26, 327-349.

Fletcher, J. and A. Marshall, 2005, An empirical examination of the benefits of international diversification, Journal of International Financial Markets, Institutions and Money,15, 455468.

Frazzini, A., Israel, R. and T. Moskowitz, 2014, Trading costs of asset pricing anomalies, Working Paper, University of Chicago.

Frost, P.A. and J.E. Savarino, 1988, For better performance: Constrain portfolio weights, Journal of Portfolio Management, 15, 29-34.

Giannetti, M. and B. Kahraman, 2017, Open-end organizational structures and limits to arbitrage, Review of Financial Studies, forthcoming.

Grauer, R.R. and N.H. Hakansson, 1993, On the use of mean-variance and quadratic approximations in implementing dynamic investment strategies: A comparison of the returns and investment policies, Management Science, 39, 856-871.

Gregory, A., Tharyan, R. and A. Christidis, 2013, Constructing and testing alternative versions of the Fama-French and Carhart models in the UK, Journal of Business Finance and Accounting, 40, 172-214.

Grubel, H., 1968, Internationally diversified portfolios: Welfare gains and capital flows, American Economic Review 58, 1299-1314.

Hansen, L.P. and R. Jagannathan, 1991, Implications of security market data for models of dynamic economies, Journal of Political Economy, 99, 225-262.

Harvey, C.R., 2017, The scientific outlook in financial economics, Working Paper, Duke University. 
Harvey, C.R. and Y. Liu, 2017, Lucky factors, Working Paper, Duke University.

He, H. and D.M. Modest, 1995, Market frictions and consumption-based asset pricing, Journal of Political Economy, 103, 94-117.

Hodrick, R.J. and X. Zhang, 2014, International diversification revisited, Working Paper, University of Columbia.

Hou, K., Xue, C. and L. Zhang, 2017, Replicating anomalies, Working Paper, Ohio State University.

Jagannathan, R. and T. Ma, 2003, Risk reduction in large portfolios: Why imposing the wrong constraints helps, Journal of Finance, 58, 1651-1684.

Jarrow, R. and P. Protter, 2017, A rational asset pricing model for premiums and discounts on closed-end funds: The bubble theory, Working Paper, Cornell University.

Kan, R. and D. Smith, 2008, The distribution of the sample minimum-variance frontier, Management Science, 54, 1364-1380.

Kan, R., Wang, X. and G. Zhou, 2017, On the value of portfolio optimization under estimation risk, Working Paper, University of Toronto.

Kan, R. and G. Zhou, 2012, Tests of mean-variance spanning, Annals of Economics and Finance, 13, 145-193.

Kandel, S., McCulloch, R. and R.F. Stambaugh, 1995, Bayesian inference and portfolio efficiency, Review of Financial Studies, 8, 1-53.

Kroll, Y., Levy, H. and H. Markowitz, 1984, Mean-variance versus direct utility maximization, Journal of Finance, 39, 47-61.

Lee, B. and G. Hong, 2002, On the dual characteristics of closed-end country funds, Journal of International Money and Finance, 21, 589-618.

Lessard, D., 1973, World, national and industry factors in equity returns, Journal of Finance 29, $379-391$. 
Lewellen, J., 2015, The cross-section of expected stock returns, Critical Finance Review, 4, $1-44$.

Li, K., Sarkar, A. and Z. Wang, 2003, Diversification benefits of emerging markets subject to portfolio constraints, Journal of Empirical Finance, 10, 57-80.

Liu, E.X., 2016, Portfolio diversification and international corporate bonds, Journal of Financial and Quantitative Analysis, 51, 959-983.

Liu, W. and N. Strong, 2008, Biases in decomposing holding period portfolio returns, Review of Financial Studies, 21, 2243-2274.

Luttmer, E.G.J., 1996, Asset pricing in economies with frictions, Econometrica, 64, 14391467.

Markowitz, H., 1952, Portfolio selection, Journal of Finance, 7, 77-91.

Michaud, R.O., 1989, The Markowitz optimization enigma: Is 'optimized' optimal, Financial Analysts Journal, 45, 31-42.

Miffre, J., 2007, Country-specific ETFs: An efficient approach to global asset allocation, Journal of Asset Management, 8, 112-122.

Parwada, J. and K.K. Siaw, 2014, Empirical test of the liquidity-based theory of closed-end funds, Working Paper, University of New South Wales.

Patro, D.K., 2001, Measuring performance of international closed-end funds, Journal of Banking and Finance, 25, 1741-1767.

Pennathur, A., Delcoure, N. and D. Anderson, 2002, The performance and diversification of iShares and closed-end country funds, Journal of Financial Research, 25, 541-557.

Sharpe, W.F., 1966, Mutual fund performance, Journal of Business, 39, 119-138.

Shleifer, A. and R.W. Vishny, 1997, The limits of arbitrage, Journal of Finance, 52, 35-55.

Shumway, T., 1997, The delisting bias in CRSP data, Journal of Finance, 52, 327-340. 
Stein, J.C., 2005, Why are most funds open-end? Competition and the limits to arbitrage, Quarterly Journal of Economics, 120, 247-272.

Tu, J. and G. Zhou, 2011, Markowitz meets Talmud: A combination of sophisticated and naïve diversification strategies, Journal of Financial Economics, 99, 204-215.

Wang, Z., 1998, Efficiency loss and constraints on portfolio holdings, Journal of Financial Economics, 48, 359-375.

Wu, Y., Wermers, R. and J. Zechner, 2016, Managerial rents vs shareholder value in delegated portfolio management: The case of closed-end funds, Review of Financial Studies, 29, 34283470.

Zellner, A., 1971, An introduction to Bayesian inference in econometrics (Wiley, New York). 